\title{
Understanding Faculty Attitudes About Distance Education: The Importance of Excitement and Fear
}

\author{
Jennifer Bunk, Rui Li, Esther Smidt, Christopher Bidetti and Brett Malize \\ West Chester University of Pennsylvania
}

\begin{abstract}
The purpose of the present study is to further understand faculty attitudes about distance education by exploring the psychological processes through which these attitudes are influenced. We explored the following research question: Do feelings of excitement versus fear mediate and/or moderate the relationship between online teaching experience and various faculty attitudes about online education? Survey data from 152 part- and full-time faculty from a midsize public university in the Mid-Atlantic region of the United States was utilized. Multiple regression analyses revealed that excitement versus fear mediates the relationship between online teaching experience and all of our outcome variables, and that excitement versus fear moderates the relationship between online teaching experience and the extent to which faculty feel that their institution is pushing too much instruction online. Our results demonstrate the importance of excitement versus fear in explaining why some faculty have negative rather than positive attitudes about distance education. Our results suggest that university administrators may find it helpful to implement policies and practices that instill a sense of excitement about distance education in all faculty.
\end{abstract}

\section{Introduction}

There is little doubt that distance education is currently in a period of growth. It has grown exponentially over the past decade, with more and more universities adopting the practice as a way of expanding their reach and students' learning options (Magiuka, Shi, \& Bonk, 2005; Shea, 2007; United States Department of Education, 2006). The Instructional Technology Council reported that between fall 
2012 and 2013 there was a 5.2\% growth rate in online student enrollment, which surpasses overall student enrollment at colleges and universities (Lokken \& Mullins, 2014). As of September 2014, about one third of professors reported that they have taught an online course (Jaschik \& Lederman, 2014).

Some faculty, however, have been resistant to online teaching, especially because the demands are higher compared to traditional courses (Murphy, Levant, Hall, \& Glueckauf, 2007). In addition, only 9\% of faculty strongly agree that online courses can be as effective as face-to-face courses (Jaschik \& Lederman, 2014.) However, on a more optimistic note, distance education instructors describe positive experiences, such as collaborative learning and rich online discussions (Rudestam, 2004). Thus, although demand for online education is growing, there is still widespread skepticism among faculty in their perceptions of online learning (Allen \& Seaman, 2006). With faculty at the forefront of the online education movement, it is important to understand their attitudes as well as factors that impact their participation in online education.

The purpose of the present study is to further understand faculty attitudes about distance education by exploring the psychological processes through which these attitudes are influenced. More specifically, we propose that both faculty experience and motivation/emotion play important roles in shaping faculty attitudes, and that excitement versus fear-as an emotional motivational factor-will both moderate and mediate the relationship between faculty online teaching experience and faculty attitudes about online education.

We expand upon previous research by focusing on excitement versus fear as a key factor in explaining faculty distance education attitudes. Our research thus has the potential to make both theoretical and practical contributions. We add to the existing body of theoretical knowledge surrounding the role that various psychological variables can play in understanding attitudes about online learning. Practically, our focus on excitement versus fear should be promising to university constituents wanting to effect positive changes related to distance education, given that excitement versus fear can be influenced in a number of ways. Unlike online teaching experience-which is difficult and not always advantageous to attempt to change- excitement versus fear can be brought about even among those faculty with little to no experience teaching online.

\section{Faculty Attitudes Toward Online Education}

A survey by Allen and Seaman (2012) of 4,564 university faculty shows faculty are especially pessimistic regarding the quality of online education, with nearly two thirds reporting they believe online learning outcomes are inferior or somewhat inferior compared to traditional face-to-face classrooms. A similar survey by the Ontario Confederation of University Faculty Association (2012) reported that 80\% of faculty either disagreed or strongly disagreed with the statement "In my opinion, online education is an effective substitute for the traditional classroom experience” (p. 5).

To keep up with the rapid growth of online education among universities, faculty have also felt the pressure from university administrators to develop and teach online courses. One third of a representative national sample of United States university faculty feel their institution is pushing for too much online education. Additionally, 58\% of faculty view the growth of online education with "more fear than excitement” (Allen \& Seaman, 2012, p. 5).

\section{Factors That Impact Faculty Attitudes}

Faculty attitudes have been shown to be caused by a variety of factors. We are specifically interested in the impact of faculty motivation/emotion and online teaching experience.

Motivation/emotion. Multiple previous studies indicate faculty are motivated to teach online due to intrinsic rewards rather than extrinsic rewards, such as monetary incentives (Maguire, 2005). Examples of intrinsic rewards include feelings of self-gratification and the personal desire to teach (Rockwell, Schauer, Fritz, \& Marx, 1999; Shea, 2007). There also seems to be a theme of self-improvement intrinsic motivators, with faculty citing the opportunity to develop new ideas, motivation to use technology, learning about pedagogy and technology, and the opportunity to improve their teaching skills (Betts, 1998; Schifter, 2000; Shea, 2007). Faculty also cited the ideas of taking on new challenges and added intellectual challenge as motivators (Zhen, Garthwait, \& Pratt, 2014; Betts, 1998; Shea, 2007). However, the most important intrinsic motivators concerned students' needs. Some of these motivators included the 
ability to reach underserved or place-bound students, greater flexibility for students, access to new student populations, meeting students' needs, and the opportunity to diversify program offerings (Betts, 1998; Hiltz, Shea, \& Kim, 2007; Maguire, 2005). It is also equally important to understand why faculty are demotivated to teach online courses. Research showed that instructors who felt that they had been required to teach online were more demotivated due to factors such as absence of face-to-face interaction, lack of opportunity to experiment with online technology, and not enough time to develop an online course (Bollinger, Inan, \& Wasilik, 2014; Shea, 2007).

Faculty experience. Researchers have shown that experience with online education has an effect on faculty's perceptions of online learning outcomes (Allen \& Seaman, 2012; Ulmer, Watson, \& Derby, 2007). Faculty overall hold a pessimistic view on the learning outcomes of students in online education (Allen \& Seaman, 2012; Ontario Confederation of University Faculty Association, 2012). Allen and Seaman further break down their findings to investigate whether faculty experience with online education plays a role in these perceptions. The results showed that three quarters of faculty with no online teaching responsibilities for the current year reported that online learning outcomes were inferior to face-to-face learning outcomes. For those faculty teaching at least one online course, only $39 \%$ believed that learning outcomes were somewhat inferior to face-to-face outcomes. Additionally, online teaching experience affects faculty attitudes of fear and excitement toward the growth of online education. Two thirds of faculty teaching online and blended courses at the same time reported more excitement than fear. Faculty without experience were likely to express more fear than excitement about online education growth.

Ulmer et al. (2007) showed interesting findings regarding faculty perceptions of online education. Faculty with distance education experiences believed students performed better in distance education, while those without distance education experiences did not. However, the experienced faculty also believed distance education caused a decline in the quality of education, while faculty without experience disagreed with that notion. While these findings may seem contradictory, they are supported by Uhlig (2002), who found that some faculty hold a preconceived attitude that distance education will compromise educational quality.

A study by Hunt, Davis, Richardson, Hammock, Akins, and Russ (2014) investigated possible reasons faculty with no experience may view online education less favorably than traditional face-to-face education. They found that inexperienced faculty were concerned about things such as their lack of training, lack of technological skills, and inability to interact with students. Shea (2007) reported that less experienced faculty reported more demotivators than experienced faculty. Unfamiliarity with effective online pedagogy, inadequate time to learn about online teaching, and concerns that offering online education might reduce the reputation of their institution were cited as concerns by inexperienced faculty.

For this study, we are interested in investigating a specific motivational factor-feelings of excitement versus fear-and how the factor mediates and/or moderates the relationships between online teaching experience and various faculty attitudes about online education. We propose excitement versus fear as a mediator because we expect it to play a key explanatory role in understanding why online teaching experience is related to faculty attitudes. We also propose excitement versus fear as a moderator because it should also affect to what degree online teaching experience affect attitudes. Our research question is as follows:

Research Question: Do feelings of excitement versus fear mediate and/or moderate the relationship between online teaching experience and various faculty attitudes about online education?

\section{Method}

\section{Participants}

Participants were 169 part- and full-time faculty from a midsize public university in the MidAtlantic region of the United States who were recruited via an e-mail inviting them to participate in an online survey on distance learning attitudes. Participation in the study was voluntary, and participants 
were free to withdraw from the study at any time without penalty. All faculty were invited to participate ( $n=718$ ) and 169 responded, yielding a 23\% response rate. Data for 17 of the participants was discarded due to failure to complete at least half of the survey (final $N=152$ ). Participants consisted of $40 \%$ males ( $n=60)$ and $60 \%(n=90)$ females. (Two respondents did not report their gender.) The breakdown of participants by college is as follows: $53 \%$ from the College of Arts and Science $(n=80), 15.2 \%$ from the College of Business and Public Affairs $(n=23)$, 8.6\% from the College of Education $(n=13), 16.6 \%$ from the College of Health Sciences $(n=25)$, and 6.6\% from the College of Visual and Performing Arts $(n=10)$. (One respondent did not report his/her college.) A majority of participants, $88.1 \%(n=133)$ reported being full-time professors, with only $11.9 \%$ part-time $(n=18)$. (One respondent did not report his/her part-time or full-time status.) Approximately half $(50.3 \%, n=76)$ of the participants were tenured, and the other half were either not tenured $(25.8 \%, n=39)$ or not tenure-track $(23.8 \%, n=28)$. (One respondent did not report his/her tenure status.) The number of years of teaching experience was measured in ranges (i.e., 1-3, 4-5, etc.). The participants' years of experience ranged from less than 1 year to more than 20 years, with a mean range of $10-15$ years. Approximately $32 \%(31.6 \%, n=48)$ of participants reported experience with teaching online courses. The ethnic breakdown of the survey respondents is as follows: $5.9 \%$ Asian or Pacific Islander $(n=9)$; $2.6 \%$ Black, African, or AfricanAmerican $(n=4)$; $1.3 \%$ Hispanic $(n=2) ; 61.2 \%$ White or European $(n=93)$; and $2 \%$ Other $(n=3)$. (The remaining $27 \%$ [ $n=41$ ] did not respond.)

\section{Measures}

At the beginning of our survey, we included questions about the following basic demographic categories: gender, ethnicity, part-time or full-time status, tenure status, and college. The remaining survey items were derived from the survey instrument used in Allen and Seaman (2012). We obtained the survey from Babson University and, with their permission, borrowed their items regarding online teaching experience, excitement versus fear around distance education, and opinions about online education. See below for more detail.

Control variables. The following variables were used as controls: gender ( $0=$ male; $1=$ female), part-time or full-time status ( 0 = part-time; $1=$ full-time $)$, number of years teaching, and tenure status $(0=$ not tenured or not tenure-track; 1 = tenured).

Online teaching experience. Participants indicated which type of courses (face-to-face, blended/hybrid, and online) they had taught in the past year and at what level (graduate, undergraduate, or other). First, a typical face-to-face course was defined as "a course where all meetings are face-to-face, may use a learning management system or web pages to post the syllabus and assignments.” The second option was a blended/hybrid course, defined as "a course where sufficient content is delivered online to create a reduction in the number of face-to-face class meetings.” The final option was an online course, which is defined as "a course in which all, or virtually all, the content is delivered online. Typically have no face-to-face class meetings." These were then coded to reflect experience with online teaching. If a participant indicated that they had experience teaching an online or blended course at the undergraduate, graduate, or other level in the latest academic year, they were considered to have online teaching experience and were coded as 1. Participants without online teaching experience were coded as 0.

Excitement versus fear. Participants were asked, "Do the following developments fill you more with excitement or with fear?" Response options included "more fear than excitement" or "more excitement than fear," and the responses were coded such that a higher score indicated more excitement than fear. The two items were "the growth of online education" and "the growth of blended/hybrid education." Cronbach's alpha reliability for these two items is $\alpha=.73$.

Outcomes. Three items were used as separate outcome variables. The item stem for these three items was "What are your opinions about the current state of online education?" Each item was rated on a 5-point Likert scale with Strongly Disagree (1) and Strongly Agree (5) as anchors. The statements participants were asked to score consisted of the following: "my institution is pushing too much instruction online," "online education can be as effective in helping students learn as in-person instruction," and "learning outcomes in an online course are superior to face-to-face." These items were borrowed from Allen and Seaman (2012). 


\section{Results}

The correlations, means and standard deviations for all study variables are reported in Table 1.

\section{Mediation Analyses}

To test whether or not feelings of excitement versus fear mediated the relationship between online teaching experience and our three outcome variables, multiple regression analyses were conducted using the three-step method suggested by Baron and Kenny (1986), which is outlined below. The following variables were used as controls: gender, part- or full-time, number of years teaching, and tenure. The first step is to establish a connection between our predictor and outcome variables. In this instance, our predictor was online teaching experience. Each of our three outcome variables was separately regressed onto the online teaching variable with the following results: "online education can be as effective in helping students learn as in-person instruction" $(\beta=.273 ; p<.001)$, "my institution is pushing too much instruction online" $(\beta=-.253 ; p<.001)$, and "learning outcomes in an online course are superior to faceto-face" ( $\beta=.224 ; p<.001)$. These results can also be viewed in Table 2, Step 1.

With the predictor showing significant relationships to all of our outcome variables, we proceeded to Step 2, which consists of showing the relationship between the predictor (online teaching experience) and the mediator (excitement versus fear). For this step, the mediator (excitement versus fear) was regressed onto the predictor (online teaching experience) $(\beta=.270 ; p<.01$; Table 2, Step 2).

With the relationship between predictor and mediator established, Step 3 was to conduct a multiple regression with both online teaching experience and excitement versus fear as predictors. To establish mediation, it was necessary to show that once excitement versus fear was added to the regression equations, the relationship between online teaching experience and the outcome variables weakens. We therefore regressed all three outcome variables onto online teaching experience and the excitement versus fear variables, the results of which are shown in Table 2 (Mediation, Step 3). Results showed that excitement versus fear mediated the impact of online teaching experience on all three outcome variables as follows: "online education can be as effective in helping students learn as face-to-face instruction" $(\beta=$ $.654 ; p<.001)$, "my institution is pushing too much instruction online" $(\beta=-.307 ; p<.001)$, and "learning outcomes in an online course are superior to face-to-face" $(\beta=.556 ; p<.001)$. As can be seen in Table 2, Step 3, online teaching experience became nonsignificant in all three cases. Thus, we can conclude that feelings of excitement versus fear mediate the relationships between online teaching experience and all three outcomes. 
Table 1 Correlations Among All Study Variables

\begin{tabular}{|c|c|c|c|c|c|c|c|c|c|}
\hline Measure & 1 & 2 & 3 & 4 & 5 & 6 & 7 & 8 & 9 \\
\hline 1. Gender & - & & & & & & & & \\
\hline 2. Part- or full-time & -.134 & - & & & & & & & \\
\hline 3. Number of years teaching & .016 & $.223 * *$ & - & & & & & & \\
\hline 4. Tenure & -.071 & $.370 * * *$ & $.540 * * *$ & - & & & & & \\
\hline 5. Online teaching experience & .035 & .032 & .003 & .109 & - & & & & \\
\hline 6. Excitement vs. fear & .157 & -.155 & -.029 & -.088 & $.256 * *$ & - & & & \\
\hline $\begin{array}{l}\text { 7. Online education can be as } \\
\text { effective in helping students } \\
\text { learn as in-person } \\
\text { instruction }\end{array}$ & $.164^{*}$ & -.041 & -.103 & -.110 & $.268 * *$ & $.677 * * *$ & - & & \\
\hline $\begin{array}{l}\text { 8. My institution is pushing too } \\
\text { much instruction online }\end{array}$ & -.023 & .116 & .137 & $.263 * *$ & $-.222 * *$ & $-.367 * * *$ & $-.394 * * *$ & - & \\
\hline $\begin{array}{l}\text { 9. Learning outcomes in an } \\
\text { online course superior to } \\
\text { face-to-face }\end{array}$ & .129 & -.106 & -.018 & -.057 & $.210^{*}$ & $.592 * * *$ & $.684 * * *$ & $-.320 * * *$ & - \\
\hline Mean & .60 & .88 & 4.99 & .50 & .32 & 2.98 & 2.8 & 3.38 & 2.16 \\
\hline$S D$ & .49 & .33 & 1.72 & .50 & .47 & .86 & 1.32 & 1.13 & 1.00 \\
\hline
\end{tabular}

$* p<.05 . * * p<.01 . * * * p<.001$.

Listwise $N=148-152$

Note. Standardized regression coefficients for separate regressions are shown. The following control variables were

Table 2

Mediation Analyses

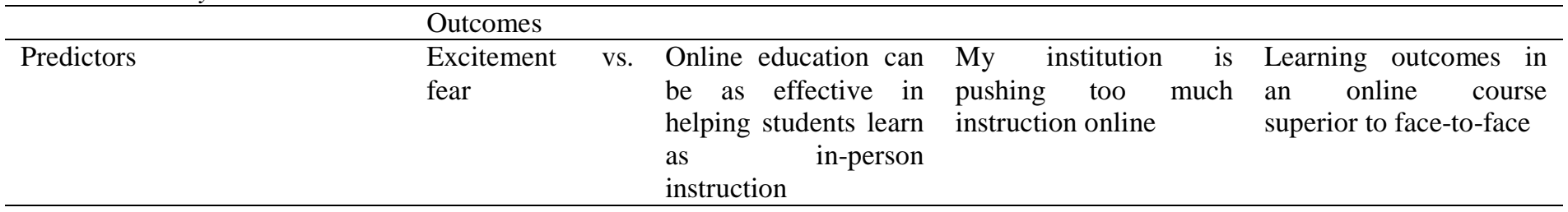

Mediation-Step 1

Online teaching experience

$.273^{* * *}$

$-.253^{* *}$

$.224^{* *}$

\section{Mediation-Step 2}

Online teaching experience $\quad .270 * *$

\section{Mediation-Step 3}

Online teaching experience

Excitement vs. fear

$\begin{array}{ccc}.091 & -.158 & .098 \\ .654 * * * & -.307 * * * & .556 * * *\end{array}$

used in all analyses: gender, part- or full-time, number of years teaching, tenure

$* p<.05 . * * p<.01 . * * * p<.001$.

Listwise $N=140-148$ 
Table 3 Moderation Analysis

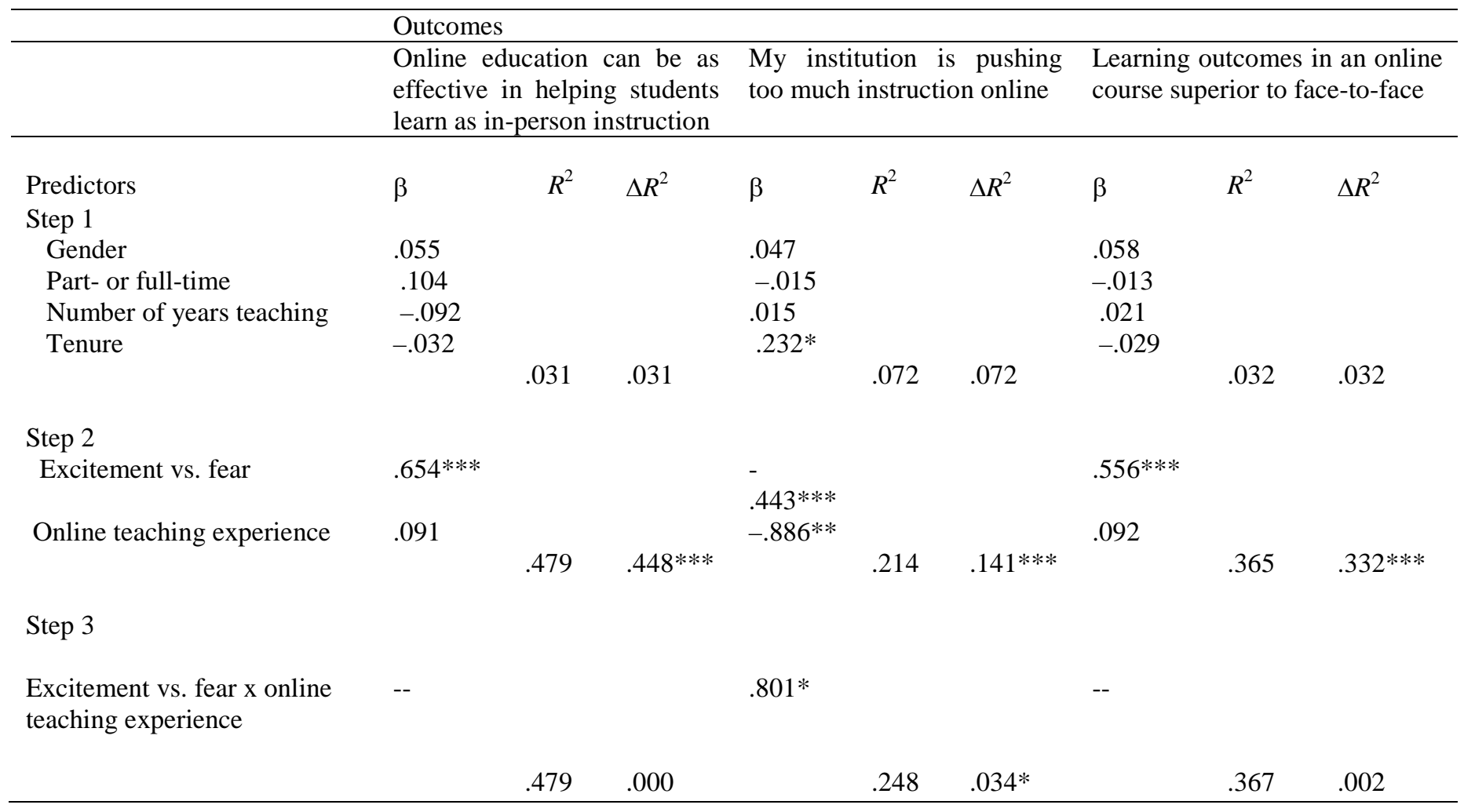

Note. Standardized regression coefficients from the best-fitting models are shown.

$* p<.05$. ** $p<.01$. *** $p<.001$.

Listwise $N=140-144$

\section{Moderation Analyses}

To test for moderation, multiple regression analyses were performed using the method suggested by Baron and Kenny (1986). Three separate regressions were conducted, one for each of our outcomes. The following control variables were entered in the first step of each regression: gender, part- or full-time, number of years teaching, and tenure. Next, the main effect variables (i.e., online teaching experience and excitement versus fear) were added in Step 2 of the regressions, and finally the two-way interaction between online teaching experience and excitement versus fear was added in the third step. A significant change in $R^{2}$ at the third step (after adding the two-way interaction) would indicate that excitement versus fear moderates the relationship between online teaching experience and the given outcome.

The results can be viewed in Table 3. Results indicate that this moderation was significant with one of our outcomes: "my institution is pushing too much instruction online" $\left(\Delta R^{2}=.034, p<.05\right)$, which showed a significant change in $R^{2}$ at Step 3. To depict this interaction, the excitement versus fear variable was dichotomized via a median split, and a graph was created to illustrate the relationship (Figure 1). As indicated by the figure, excitement versus fear and online teaching experience interacted to predict the extent to which respondents felt that their institution was pushing too much online instruction. Those who felt more fear and had no experience indicated the highest levels of agreement that their institution is pushing too much online education. However, interestingly, those who felt more excitement and had no experience indicated the lowest levels of agreement. 


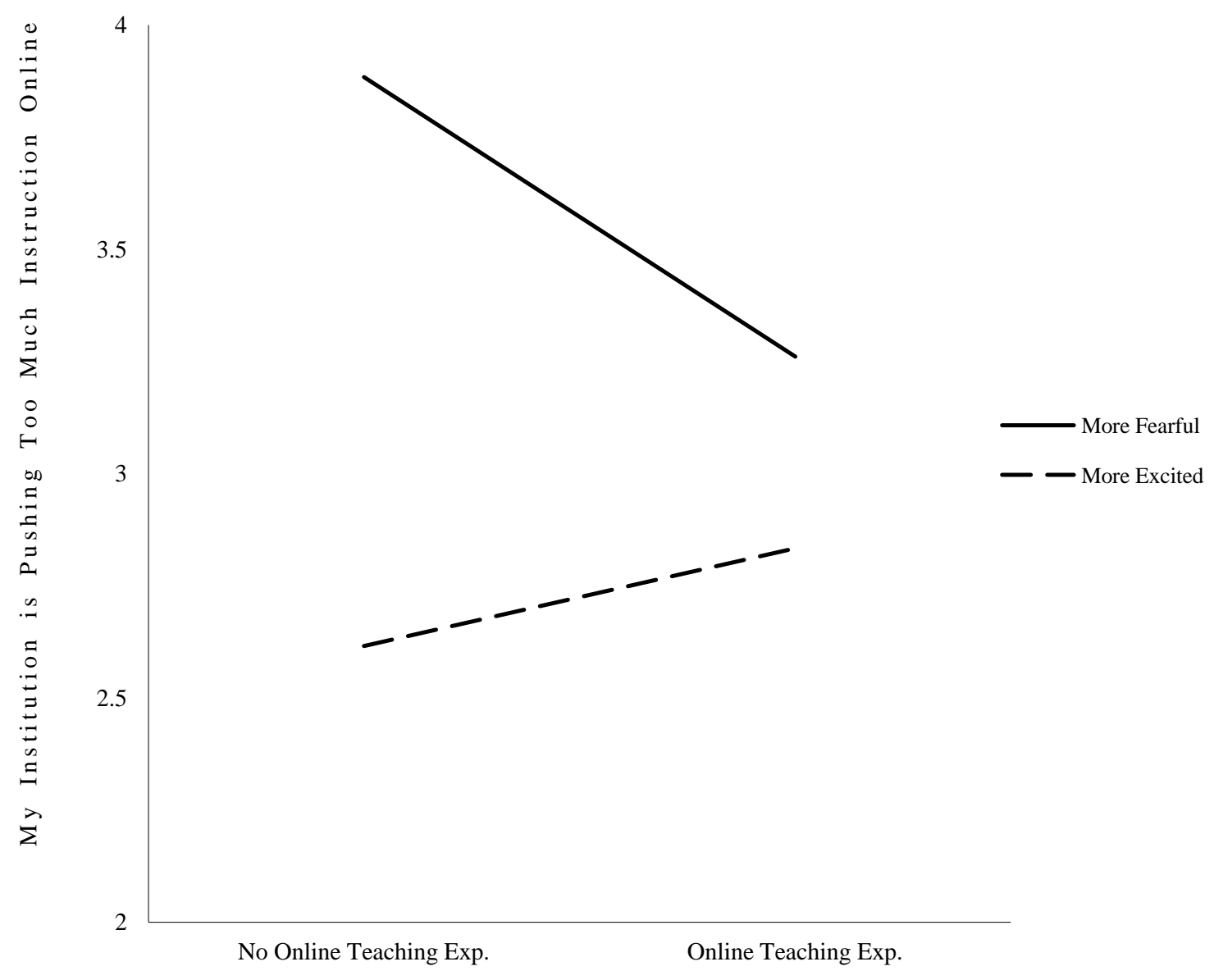

Figure 1: Excitement vs. fear moderates the relationship between online teaching experience and the belief that the institution is pushing too much instruction online.

\section{Discussion}

For this study, we were interested in investigating a specific emotional factor-feelings of excitement versus fear-and how the factor mediates and/or moderates the relationships between online teaching experience and various faculty attitudes about online education. Our research question was "Do feelings of excitement versus fear mediate and/or moderate the relationship between online teaching experience and various faculty attitudes about online education?” The results showed that feelings of excitement versus fear mediate the relationships between online teaching experience and all three outcome variables. This is not surprising, as the literature review indicates that both faculty motivation/emotion and faculty online teaching experience are important factors that impact faculty attitudes about online education. Our study highlights the importance of motivation/emotion in explaining the relationship between online teaching experience and outcomes.

Further investigation through moderation analyses revealed that feelings of excitement versus fear and online teaching experience interacted to predict the extent to which faculty felt that their institution is pushing too much education online. As one might expect, when faculty had more fear than excitement and had no experience teaching online, they reported the highest levels of agreement that their 
institution is pushing for too much online education. Interestingly, those who felt more excitement than fear and had no experience teaching online indicated the lowest levels of agreement, not those who felt more excitement than fear and had more online teaching experience.

Thus, feelings of excitement versus fear not only play a large role in explaining why online teaching experience relates to outcomes (as revealed in our mediation analyses) but also help explain to what degree teaching experience relates to outcomes (revealed in our moderation analyses). On the other hand, the nonsignificant moderations with two of our outcome variables, "online education can be as effective in helping students learn as in-person instruction" and "learning outcomes in an online course are superior to face-to-face," show that feelings of excitement and/or fear did not interact with online teaching experience to predict how faculty felt about the effectiveness and learning outcomes of online education. This suggests that feelings of excitement and/or fear do not have as significant an impact on faculty views of the quality of online education-namely teaching effectiveness and student learning outcomes.

To put it in a nutshell, our study shows that feelings of excitement and/or fear do mediate and moderate the relationship between online teaching experience and various faculty attitudes about online education. However, the moderation effect exists only on faculty attitudes toward institutional pressure to put courses online but not on faculty attitudes toward online education quality, effectiveness, and learning outcomes, which we believe are important aspects of faculty attitudes.

Our research is not without its limitations. The cross-sectional nature of our data prevent us from making causal inferences regarding the relationship between excitement versus fear and faculty attitudes. Future research using longitudinal data could help us to address this issue. In addition, given that all of our data was self-reported, we cannot rule out respondent biases as potential explanations for our findings. Future research using multisource data (e.g., faculty performance data provided by administrators) would thus be useful. Also, given that our results are based on only a small set of outcomes, future research should explore additional attitudinal, behavioral, and affective outcomes.

\section{Conclusion}

On the one hand, distance education is growing (Lokken \& Mullins, 2014; Magiuka et al., 2005; Shea, 2007; U.S. Department of Education, 2006), and some faculty are optimistic about this development (Rudestam, 2004). On the other hand, some faculty are resistant (Allen \& Seaman, 2012; Murphy et al., 2007). Thus, there is a pressing need to learn more about faculty attitudes toward distance education. In particular, we need to further understand how faculty motivation and emotion affect their attitudes. In this study, we were able to demonstrate that feelings of excitement and fear can explain why some faculty have negative rather than positive attitudes about distance education. Our results suggest that university administrators may find it helpful to implement policies and practices that instill a sense of excitement about distance education in all faculty - whether they have experience teaching online or not.

This excitement may lead to less resistance and a more favorable climate for exploring the possibilities of online education.

\section{References}

Allen, I. E., \& Seaman, J. (2006). Growing by degrees: Online education in the United States, 2005. Sloan Consortium (NJ1).

Allen, I. E., \& Seaman, J. (2012). Conflicted: Faculty and online education, 2012. Babson Survey Research Group. 
Understanding Faculty Attitudes About Distance Education: The Importance of Excitement and Fear

Baron, R. M., \& Kenny, D. A. (1986). The moderator-mediator variable distinction in social psychological research: Conceptual, strategic, and statistical considerations. Journal of Personality and Social Psychology, 51(6), 1173-1182.

Betts, K. S. (1998). Factors influencing faculty participation in distance education in postsecondary education in the United States: An institutional study. Online Journal of Distance Learning Administration, 1(3). Retrieved from http://www.westga.edu/ distance/betts13.html

Bollinger, D., Inan, F., \& Wasilik, O. (2014). Development and validation of the online instructor satisfaction measure. Educational Technology \& Society, 17(2), 183-195.

Hiltz, S. R., Shea, P., \& Kim, E. (2007). Using focus groups to study ALN faculty motivation. Journal of Asynchronous Learning Networks, 11(1), 107-124.

Hunt, D., Davis, K., Richardson, D., Hammock, G., Akins, M., \& Russ, L. (2014). It is (more) about the students: Faculty motivations and concerns regarding teaching online. Online Journal of Distance Learning Administration, 17(2),

Jaschik, S., \& Lederman, D. (2014). The 2014 Inside Higher Ed survey of faculty attitudes on technology. Conducted by Gallup.

Lokken, F., \& Mullins, C. (2014). Trends in elearning: Tracking the impact of elearning at community colleges. 2013 Distance Education Survey Results. Washington, DC: Instructional Technology Council.

Magiuka, R. J., Shi, M., \& Bonk, C. J. (2005). Critical design and administrative issues in online education. Online Journal of Distance Learning Administration, 8(4).

Maguire, L. L. (2005). Literature review-Faculty participation in online distance education: Barriers and motivators. Online Journal of Distance Learning Administration, 8(1)

Murphy, M. J., Levant, R. F., Hall, J. E., \& Glueckauf, R. L. (2007). Distance education in professional training in psychology. Professional Psychology: Research and Practice, 38(1), 97-103.

Ontario Confederation of University Faculty Association. (2012). Faculty views on proposed changes to undergraduate education. Retrieved from http://ocufa.on.ca/assets/Faculty-Survey-Part-2Government-Proposals-FINAL.pdf

Rockwell, S. K., Schauer, J., Fritz, S. M., \& Marx, D. B. (1999). Incentives and obstacles influencing higher education faculty and administrators to teach via distance. Online Journal of Distance Learning Administration, 2(4).

Rudestam, K. E. (2004). Distributed education and the role of online learning in training professional psychologists. Professional Psychology: Research and Practice, 35(4), 427-432.

Shea, P. (2007). Bridges and barriers to teaching online college courses: A study of experienced online faculty in thirty-six colleges. Journal of Asynchronous Learning Networks, 11(2), 73-128.

Schifter, C. C. (2000). Faculty participation in asynchronous learning networks: A case study of motivating and inhibiting factors. Journal of Asynchronous Learning Networks, 4(1), 15-22. 
Uhlig, G. E. (2002). The present and future of distance learning. Education, 122(4), 670-673.

Ulmer, L. W., Watson, L. W., \& Derby, D. (2007). Perceptions of higher education faculty members on the value of distance education. The Quarterly Review of Distance Education, 8(1), 59-70.

United States Department of Education. (2006). The condition of education, 2006. National Center for Education Statistics, NCES 2006-071. Washington, DC: U.S. Government Printing Office.

Zhen, Y., Garthwait, A., \& Pratt, P. (2014). Factors affecting faculty members' decision to teach or not to teach online in higher education. Online Journal of Distance Learning Administration, 17(4). Retrieved from http://www.westga.edu/ distance/ojdla/fall113/zhen113.html 